\title{
A Damage Constitutive Model of Rock under Hydrochemical Cyclic Invasion
}

\author{
Lunan Sun, ${ }^{1}$ Yu Zhang, ${ }^{1}$ Zhe Qin (D), ${ }^{1,2}$ Tengfei Wang, ${ }^{1}$ and Sheng Zhang ${ }^{1}$ \\ ${ }^{1}$ College of Civil Engineering and Architecture, Shandong University of Science and Technology, Qingdao, China \\ ${ }^{2}$ Shandong Key Laboratory of Civil Engineering Disaster Prevention and Mitigation, \\ Shandong University of Science and Technology, Qingdao, China \\ Correspondence should be addressed to Zhe Qin; chin@sdust.edu.cn
}

Received 13 May 2020; Revised 24 June 2020; Accepted 10 July 2020; Published 8 August 2020

Academic Editor: Zhiqiang Yin

Copyright (c) 2020 Lunan Sun et al. This is an open access article distributed under the Creative Commons Attribution License, which permits unrestricted use, distribution, and reproduction in any medium, provided the original work is properly cited.

\begin{abstract}
In order to analyze the stability of water-related materials, the deterioration and damage of rock strength due to circulating water intrusion in an open tailings pond were studied. Uniaxial compression tests were carried out for rocks under different hydrochemical environments and varying numbers of invasion cycles. Results show that, with increasing number of cycle times, rock peak strength and elastic modulus gradually decrease and the acidity and alkalinity of the soaking solution also degrades rock strength. The curve of the number of cycles, acidity, alkalinity, peak strength, and elastic modulus is fit numerically. Based on the principle of damage mechanics, a hydraulic-chemistry-mechanics (HCM) coupling damage variable is defined. Based on the theory of microbody strength distribution, the constitutive equation for rock damage under the coupled effect of water chemistry and cyclic water invasion is established. The results verify the validity of the established damage constitutive model.
\end{abstract}

\section{Introduction}

Abandoned open pits are geological bodies with increased safety risks when the original support system fails. In order to make abandoned open pits reusable and avoid wasting land resources on new tailings storage, some open pits are used as tailings ponds for nearby dressing plants [1-5]. Using an open-pit mine as a tailings pond raises two main problems. First, the waste tailings liquid contains a large amount of tailings sand and is discharged into the pit through a pipe or tanker, which causes the water level in the open pit to continuously rise. Increased groundwater flow and precipitation can also cause the water level to significantly increase. Secondly, the tailings liquid in the open pit undergoes long-term precipitation, and the tailings sand consolidates and settles. The ore pit uses the water in the pit for secondary use at various times, resulting in a decrease in water level. Therefore, after the open-pit mine is used as a tailings pond, the stability of the slope rock mass needs to be analyzed and the influence of the rock environment and water level fluctuation on the rock strength needs to be considered. At present, many researchers have examined the strength of engineering rock masses affected by water level fluctuations, primarily including the static and dynamic rocks characteristics such as compressive strength and elastic modulus. There are numerous research results on the variation in macroscopic strength of rocks under the effect of cyclic water invasion [6-12]. The weakening of rock strength under the effect of cyclic water intrusion is the damage of the micro-meso rock structure inside. Structural control theory in engineering geology indicates that cyclic water intrusion causes the expansion of primary defects such as microcracks and micropores and also causes the development of secondary defects, eventually leading to the formation of macrocracks inside the rock mass, which affects the macrostrength of the rock. Presently, for rock mesodamage characteristics under cyclic water intrusion, scanning electron microscopy and Computed Tomography (CT) tests are 
primarily used. Fractured sections of the rock are examined using advanced instruments such as nuclear magnetic resonance imagers to obtain mesostructural changes for different cyclic invasion conditions and produce a qualitative analysis of the mesodamage. Using digital image recognition technology, mesostructural information, such as fractal dimension and porosity, is extracted to quantitatively characterize the mesostructural damage [3, 13-16]. Results show that cyclic water intrusion affects the strength and structure of rocks and adversely affects the stability of the project. However, the rocks on the bank slope of the tailings reservoir are immersed in acidic or alkaline tailings for a long time. The tailings with different acidity and alkalinity will have a nonnegligible degradation effect on the macrodamage and mesodamage of the rock. For different water chemical environmental conditions, there is still a lack of necessary research on rock damage characteristics. Therefore, examining the degradation and damage characteristics of rock strength relative to water chemistry and cyclic invasion is significant, especially for wading geotechnical and coastal geotechnical engineering.

Taking the open pit as the tailings pond, the change in rock strength under the influence is examined, considering the degradation and damage to rock strength due to the coupled effect of water chemistry and cyclic invasion. Using the uniaxial compression of rocks under different hydrochemical environments, the experiment focused on analyzing the rock strength damage and established a multiparameter variation plane equation. Based on the principle of Hydraulic-Chemistry-Mechanics (HCM), coupling damage variables were defined and constructed.

\section{Engineering Background}

The Cangshang open pit was closed in 2005 and has remained idle. Due to the construction of an 8,000-ton ore dressing plant adjacent to the Sanshandao Gold Mine, the Cangshang open pit was converted to a tailings pond for the Sanshandao Gold Mine Concentrator in 2009. With the discharge of abandoned tailings fluids, the water level in the open-pit mine continues to rise, which severely affects the stability of the slope (Figure 1). The main sliding area is located on the north side of the slope. Obvious cracks are visible at the top of the slope, and there is significant slip on the local sliding surface as well as a substantial collapse of the adjacent house wall. The open pit water level rise and fall cycles cause irreversible deterioration to the rock strength and internal structure of the slope, especially for slopes containing weak structural planes, such alteration zones are formed during gold mineralization. The alteration zone has a certain strength, and the slope is in a relatively stable state. When the water invades, the rock strength decreases or the rock mass fails, which causes the pit slope to slip and even causes sudden slope instabilities.

The cyclic water invasion-dehydration effect weakens the rock mass strength and causes the open pit slope to slip. The YCY-3 water level automatic measuring instrument is used to monitor the surface displacement of the open pit north side and the open pit water level change (Figure 2). The water level of the tailings dam in the figure shows an increasing trend of first falling and then rising. When the water level falls rapidly or rises rapidly, the slope structure of the bank slope is likely to be unstable, causing serious landslides, displacements, and other disasters.

\section{Uniaxial Compression Test}

3.1. Uniaxial Compression Test Curve. The rock samples are taken from the typical rock samples of the tailings dam slope of Sanshan Island Gold Mine. The method is to use on-thespot sampling with the method of combining the core and the block on the slope surface. The drilled cores are encapsulated with plastic wrap in time to ensure their original moisture content. The rock sampled on-site is cut into standard rock specimens of $100 \mathrm{~mm} \times 50 \mathrm{~mm}$. Here, one cycle of water infiltration is defined as the rock being soaked in the soaking box for 24 hours and then dried in the drying box at $105^{\circ} \mathrm{C}$ for 24 hours. The test consists of three sets of rock samples, each group of 4 rock samples; the rock samples were subjected to 0 , 5,15 , and 30 cycles of water infiltration test, and then the samples were then immersed in a solution of $\mathrm{pH}=5, \mathrm{pH}=7$, and $\mathrm{pH}=9$ for 24 hours. A uniaxial compression test machine is used to conduct uniaxial compression tests on rocks treated with different water chemical environments at varying cycles. The basic mechanical parameters of the rock under different conditions can be obtained based on the rock stress-strain curve (Figure 3).

According to the uniaxial compression test results, the various hydrochemical environments and cyclic states have varying degrees of influence on rock mechanical properties. The stress-strain curves show four stages, including the compaction stage, elastic stage, plastic deformation stage, and yield stage. Affected by different $\mathrm{pH}$ levels and cyclic water invasion, the peak strength of the rock shows a significant decrease, which is closely related to the $\mathrm{pH}$ and the number of cyclic water intrusions. The peak strength and elastic modulus of the rock are obtained according to the uniaxial compressive stress-strain curve. The quantitative mechanical parameters are given in Table 1 :

With the increase of the number of cycles, the peak strength and elastic modulus of the rock showed an overall downward trend. The degradation rate of the rock was faster during the first 5 cycles of water intrusion, and the degradation rate after 15 cycles was relatively slow. Acid and alkali also have obvious degradation effect on rock peak strength and elastic modulus. The degradation effect of acid solution on rock is stronger than that of alkaline solution, and neutral solution has the weakest degradation effect on rock.

\subsection{Degradation of Uniaxial Compressive Strength.} Parameters such as rock strength weakening coefficient and elastic modulus degradation under different conditions are obtained from the uniaxial compression test results. The changes in the abovementioned mechanical parameters can be used to quantitatively characterize the degree of rock damage. Define the rock weakening coefficient and the deterioration degree of elastic modulus shown as follows: 


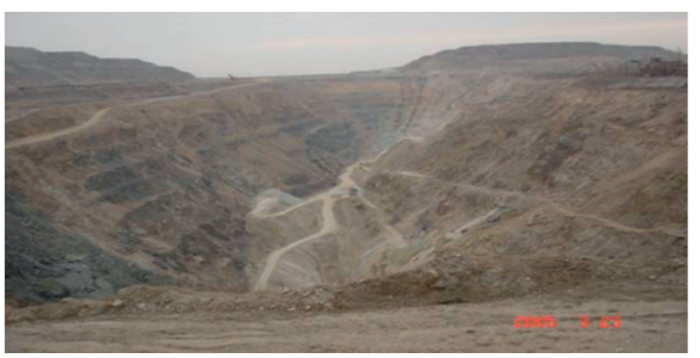

(a)

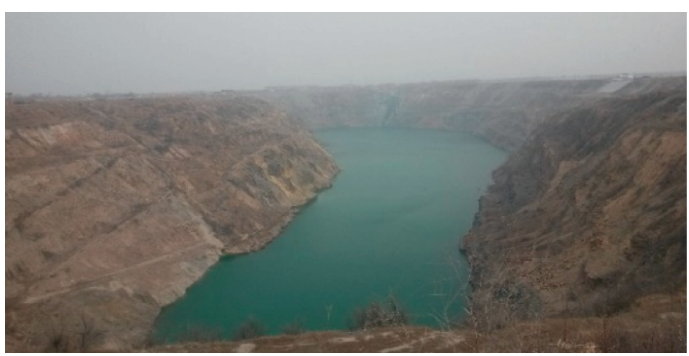

(c)

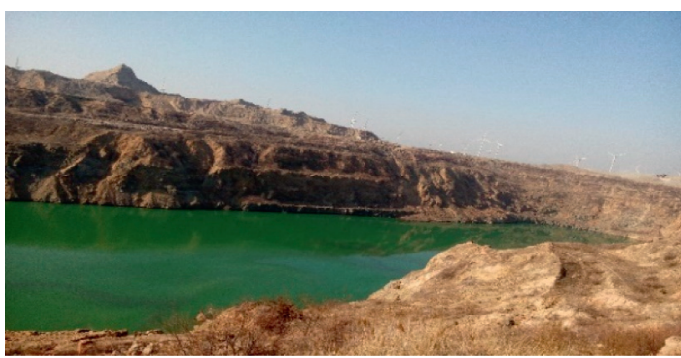

(b)

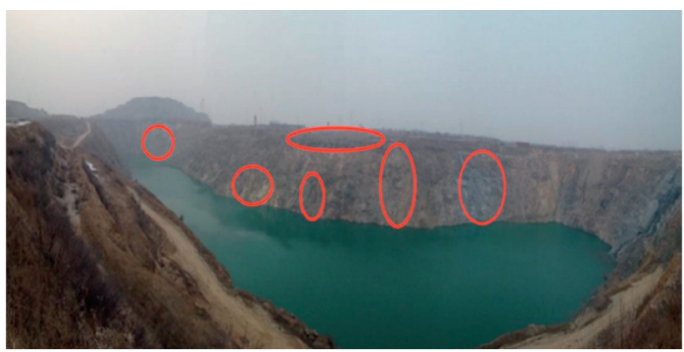

(d)

Figure 1: Cyclic invasion-dehydration process in open pit. (a) Open pit without water. (b) Water level rise. (c) Water level decline. (d) Open pit slope deformation.

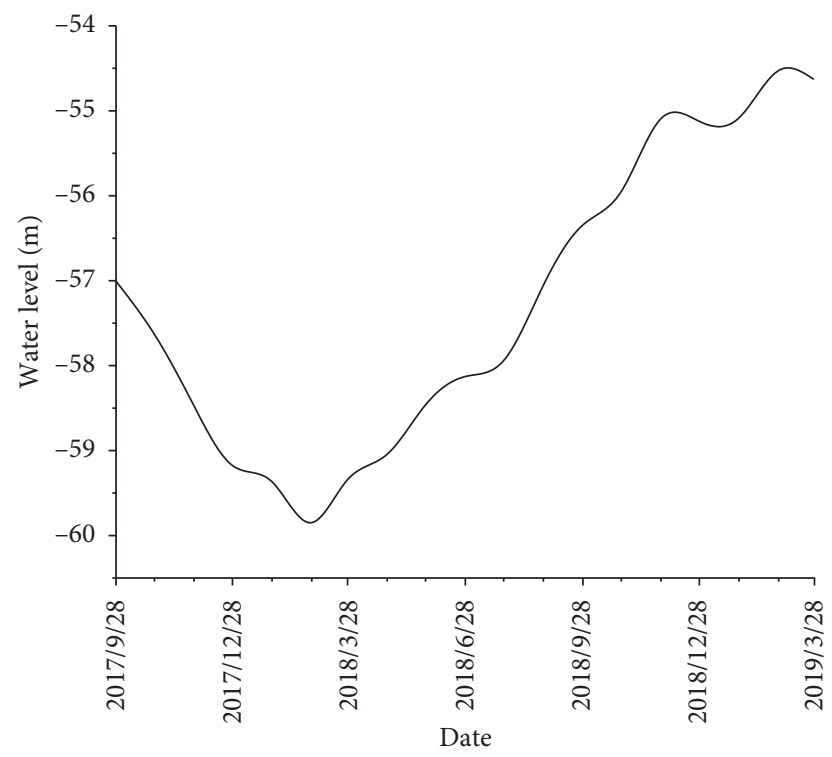

Figure 2: Water level change in the open pit.

$$
\begin{gathered}
\lambda=\frac{R_{t 0}-R_{t n}}{R_{t 0}}, \\
D_{E}=\frac{E_{0}-E_{n}}{E_{0}},
\end{gathered}
$$

where $\lambda$ is the rock weakening coefficient, $R_{t 0}$ is the initial peak strength of the rock in the natural state, $R_{t n}$ is the peak strength when the number of cycles of water intrusion is $n$; $D_{E}$ is the degree of degradation of the elastic modulus, $E_{0}$ is the initial elastic modulus of the rock in the natural state, and $E_{n}$ is the modulus of elasticity when the number of cycles of water intrusion is $n$.
The rock damage parameters for different hydrochemical environments and different cyclic states were obtained. The rock damage parameters under different cyclic states are shown in Table 2.

According to Table 2 and Figure 4, for the same water chemical environment, rock strength gradually decreases with increasing number of cycles. Similarly, for the same cycle number of cycles, rock strength gradually decreases under different $\mathrm{pH}$ levels. However, for acidic and alkaline environments, the decrease in rock strength in acidic environments is higher than in alkaline environments because the rocks are primarily carbonate rocks, and acidic ions easily breakdown carbonate, resulting in a reduction in rock strength.

By analyzing the effects of different water chemical environments and different cyclic states on the peak rock strength and elastic modulus, a mathematical fit was used to achieve a flat fit of the test results. The fitting results are shown in Figure 5 and the corresponding fitting formula is as follows.

Data were fit using the fitting toolbox in MATLAB to get the fitting formula:

$$
\begin{aligned}
& f_{1}(x, y)=11.44-2.03 x+12.88 y+0.03 x^{2}-0.87 y^{2} \\
& f_{2}(x, y)=-4.16-0.18 x+3.11 y+0.003 x^{2}-0.22 y^{2}
\end{aligned}
$$

\section{Rock Damage Constitutive Model}

Uniaxial compression tests have shown that the coupling of water chemistry and cyclic water intrusion can cause rock strength degradation, and different environmental conditions have different degrees of impact on rock strength. 


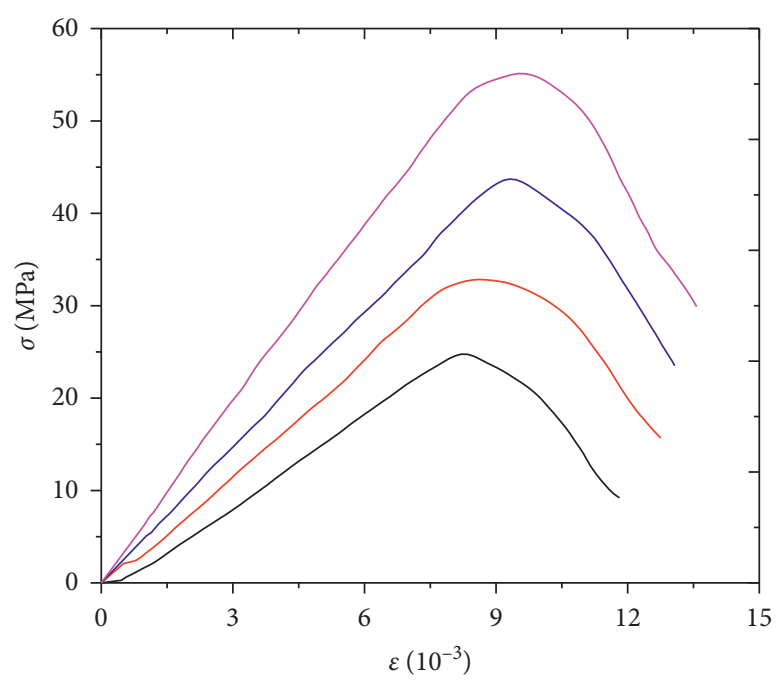

Number of cycles $=30-$ Number of cycles $=5$
Number of cycles $=15-$ Number of cycles $=0$

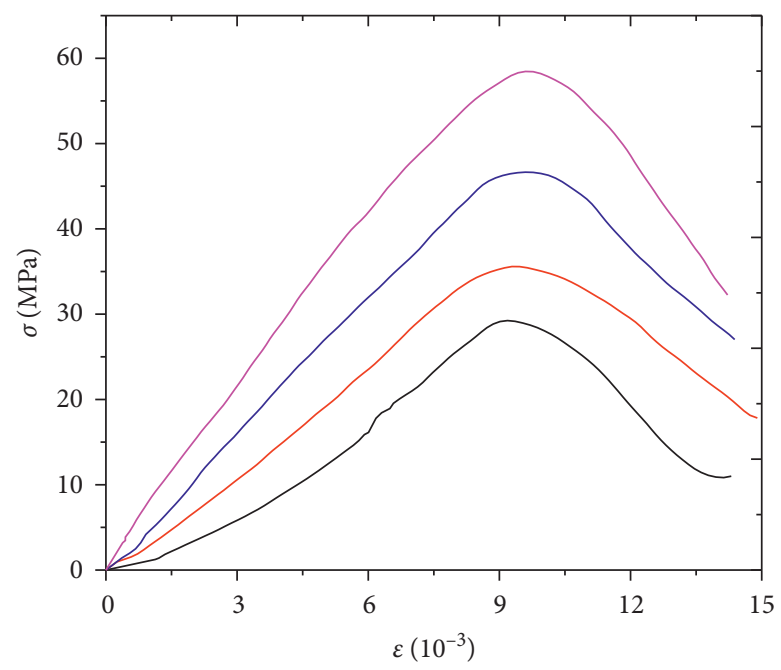

- Number of cycles $=30$ Number of cycles $=5$ - Number of cycles $=15$ - Number of cycles $=0$

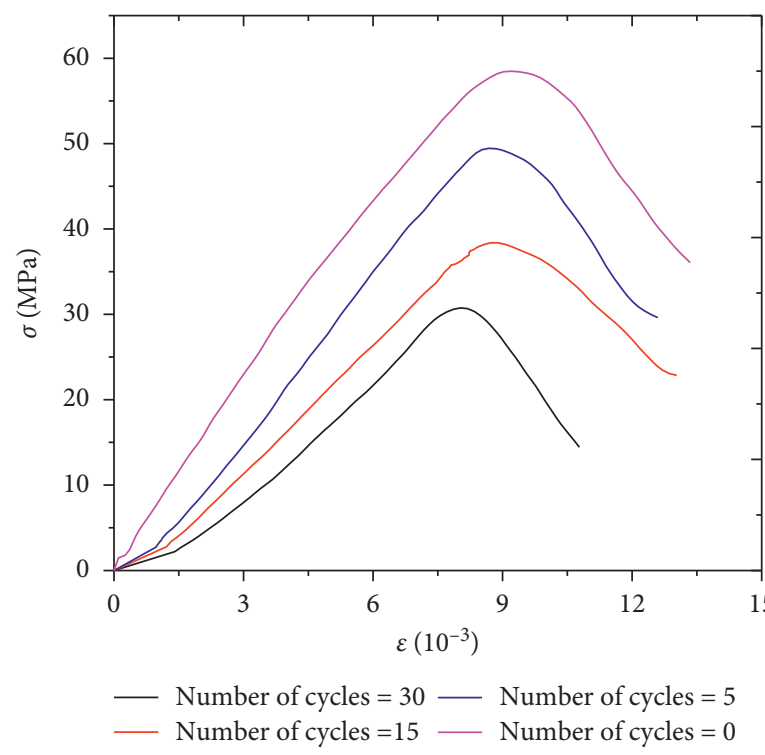

Figure 3: Stress-strain curve of rock. (a) $\mathrm{pH}=5$. (b) $\mathrm{pH}=7$. (c) $\mathrm{pH}=9$.

TABLE 1: Uniaxial compression test results.

$\mathrm{pH}=5 \quad \mathrm{pH}=7 \quad \mathrm{pH}=9$

$n$ Peak strength (MPa) Elastic modulus (GPa) Peak strength (MPa) Elastic modulus (GPa) Peak strength (MPa) $\begin{gathered}\text { Elastic } \\ \text { modulus (GPa) }\end{gathered}$

\begin{tabular}{lllllll}
\hline 0 & 55.12 & 6.15 & 58.48 & 6.67 & 58.45 & 6.35 \\
5 & 43.70 & 4.82 & 49.45 & 6.35 & 46.65 & 5.22 \\
15 & 32.83 & 4.15 & 38.38 & 4.91 & 35.58 & 4.18 \\
30 & 24.75 & 3.29 & 30.75 & 4.46 & 29.24 & 3.04 \\
\hline
\end{tabular}

Therefore, the coupling effect of water chemistry and cyclic water intrusion is affected by the coupling of cyclic water intrusion. Therefore, the damage variable in this paper is defined as the cyclic water invasion Hydraulic-ChemistryMechanics (HCM) coupling damage variable. Among them, the cyclic hydraulic (chemistry) damage variable primarily affects mechanical parameters by affecting the internal structure of the rock. According to the principle of damage mechanics, the damage variable is defined by the elastic modulus and the damage caused by mechanical loading. Since the damage is primarily due to the influence of the strength of the unit body inside the rock, the damage 
TABLE 2: The rock damage parameters for different hydrochemical environments and different cyclic states.

\begin{tabular}{|c|c|c|c|c|c|c|}
\hline \multirow[b]{2}{*}{$n$} & \multicolumn{2}{|r|}{$\mathrm{pH}=5$} & \multicolumn{2}{|r|}{$\mathrm{pH}=7$} & \multicolumn{2}{|c|}{$\mathrm{pH}=9$} \\
\hline & $\begin{array}{c}\text { Weakening } \\
\text { coefficient (\%) }\end{array}$ & $\begin{array}{l}\text { Degree of elastic modulus } \\
\text { degradation (\%) }\end{array}$ & $\begin{array}{c}\text { Weakening } \\
\text { coefficient (\%) }\end{array}$ & $\begin{array}{c}\text { Degree of elastic modulus } \\
\text { degradation }(\%)\end{array}$ & $\begin{array}{c}\text { Weakening } \\
\text { coefficient }(\%)\end{array}$ & $\begin{array}{c}\text { Degree of elastic } \\
\text { modulus } \\
\text { degradation (\%) }\end{array}$ \\
\hline 0 & 0 & 0 & 0 & 0 & 0 & 0 \\
\hline 5 & 20.72 & 21.63 & 15.44 & 4.80 & 20.19 & 17.80 \\
\hline 15 & 24.87 & 13.90 & 22.39 & 22.68 & 23.73 & 19.92 \\
\hline 30 & 24.61 & 20.72 & 19.88 & 9.16 & 17.82 & 12.92 \\
\hline
\end{tabular}
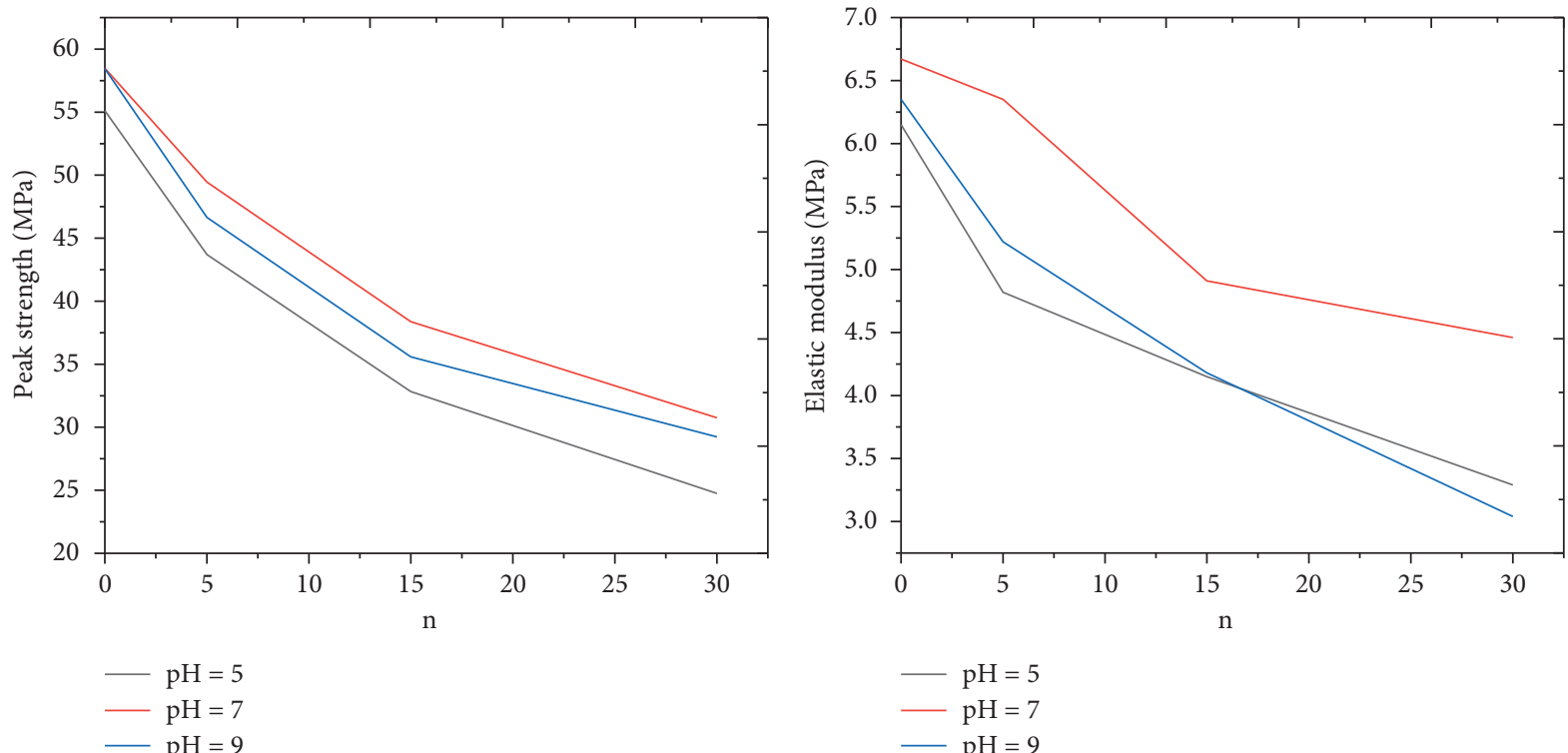

FIgURE 4: Change of mechanical parameters with the number of cycles.
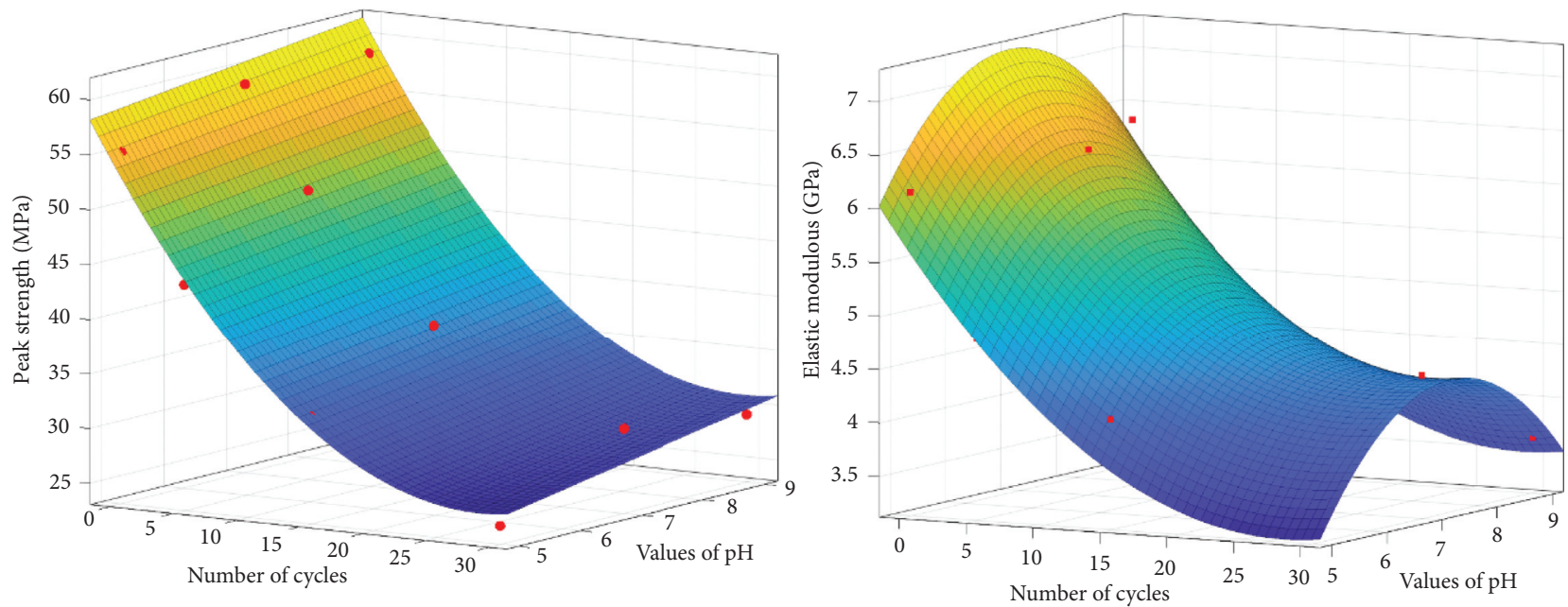

Figure 5: Parameter plane fitting.

variable is defined according to the change in the strength of the microbody.

(1) Hydraulic-chemistry damage variables: the hydraulic-chemistry damage variable primarily affects rock mechanical parameters by affecting the internal structure of the rock; therefore, according to the principle of damage mechanics, the damage variable is defined by the elastic modulus:

$$
D_{e}=\frac{E_{0}-E_{n}}{E_{0}}=1-\frac{E_{n}}{E_{0}}
$$




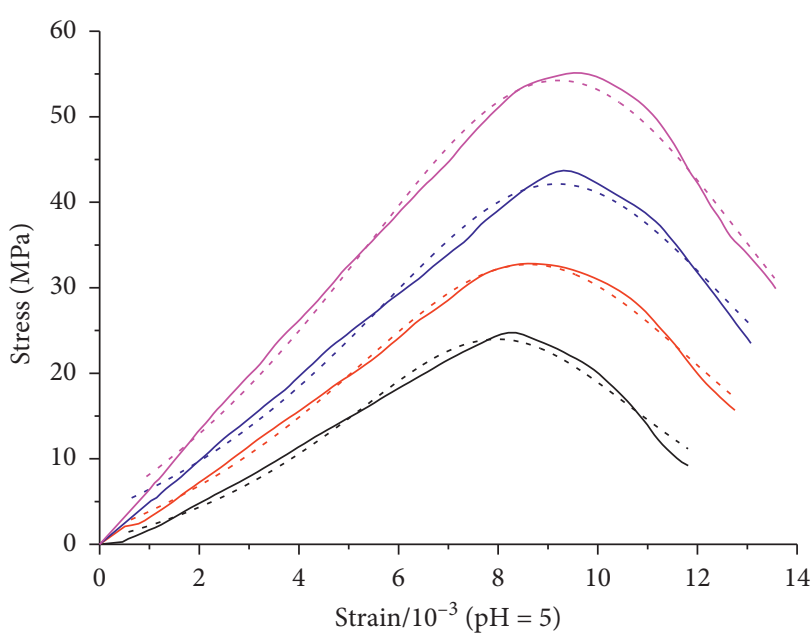

- Number of cycles $=30$

- Number of cycles $=15$

- Number of cycles $=5$

- Number of cycles $=0$

- - Number of cycles $=30$ (model curve)

- - - Number of cycles $=15$ (model curve)

- - - Number of cycles $=5$ (model curve)

- - - Number of cycles $=0$ (model curve)

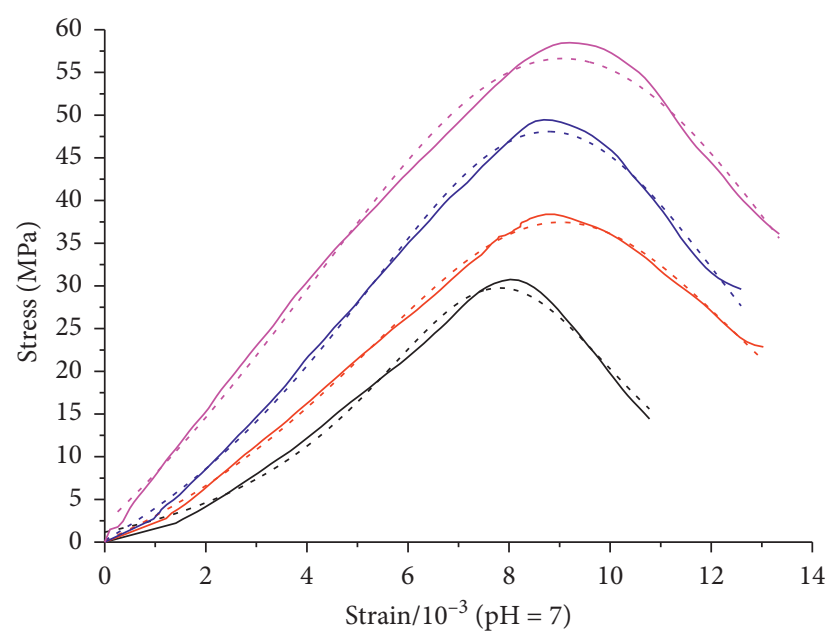

- Number of cycles $=30$

- Number of cycles $=15$

- Number of cycles $=5$

- Number of cycles $=0$

- - - Number of cycles $=30$ (model curve)

- - - Number of cycles $=15$ (model curve)

- - - Number of cycles $=5$ (model curve)

- _ - Number of cycles $=0$ (model curve)

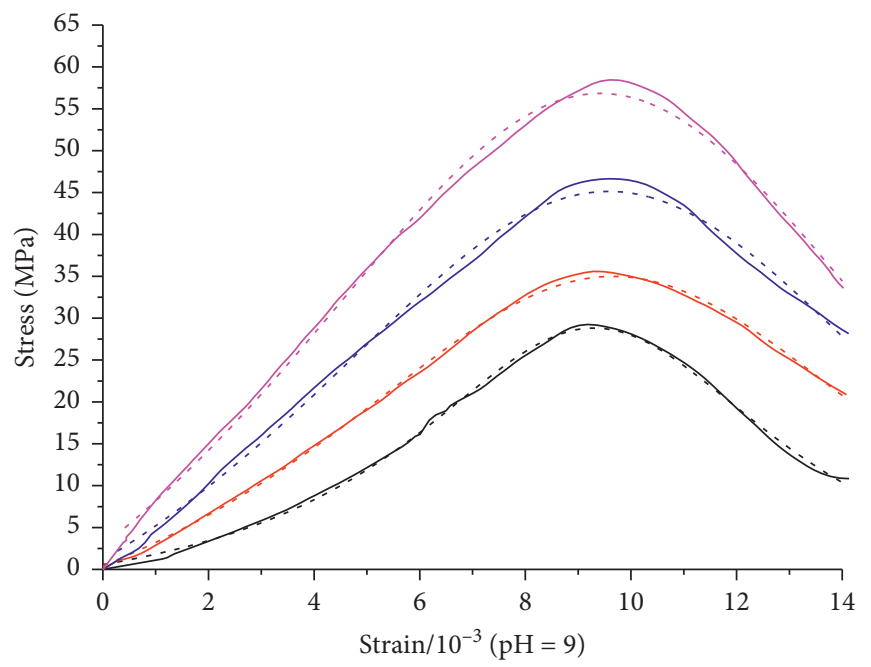

- Number of cycles $=30$

- Number of cycles $=15$

- Number of cycles $=5$

- Number of cycles $=0$

- - - Number of cycles $=30$ (model curve)

- - - Number of cycles $=15$ (model curve)

- - - Number of cycles $=5$ (model curve)

- - - Number of cycles $=0$ (model curve)

Figure 6: Comparison of test and model curves.

where $D_{e}$ denotes the hydraulic-chemical damage variable; $E_{n}$ is the elastic modulus at $n$ number of cycles; and $E_{0}$ is the elastic modulus at 0 cycles.

(2) Mechanical damage variable: during the uniaxial compression test, the external load will cause random damage to the internal unit of the test rock. The strength of the unit body is mainly distributed within a certain range, and the strength of the unit body smaller or larger than this range gradually decreases with increasing distance. Therefore, based on the knowledge of probability theory, it is assumed that the failure of the internal microunits in the rock as a whole obeys a certain probability statistical distribution, such as the Weibull distribution or Gaussian 
distribution [15]. Assuming that the strength of the rock microelements obeys the Weibull distribution, the distribution probability density function is $[17,18]$

$$
f(x)=\frac{m}{\lambda}\left(\frac{N}{\lambda}\right)^{m-1} \exp \left[-\left(\frac{N}{\lambda}\right)^{m}\right],
$$

where $m$ and $\lambda$ are Weibull distribution parameters.

The mechanical damage variable $D_{m}$ is defined as the strength failure probability of rock microelements:

$$
D_{m}=\frac{N_{b}}{N}=\frac{\int_{0}^{\varepsilon} N \cdot f(x) d x}{N}=\int_{0}^{\varepsilon} f(x) d x=1-\exp \left(-\left(\frac{\varepsilon}{\lambda}\right)^{m}\right) .
$$

Under the coupling effect of water chemistry and cyclic invasion, rocks are affected by HCM coupling of cyclic intrusion. According to formulas (3) and (5), the cyclic invasion HCM coupling damage variable is defined as follows:

$$
1-D=\left(1-D_{e}\right)\left(1-D_{m}\right)
$$

According to the above formula, the comprehensive damage variable under the HCM coupling is

$$
D=1-\frac{E_{n}}{E_{0}} \cdot\left(\exp \left(-\left(\frac{\varepsilon}{\lambda}\right)^{m}\right)\right)
$$

Damage mechanics is a recently developed discipline for studying the failure process of materials based on continuum thermodynamics. Damage mechanics focuses on the development of defects such as micropores in rocks and is the study of the formation of macroscopic cracks in materials. The principle of damage mechanics proposes the strain equivalent principle combined with the effective stress principle, in which the basic form of the damage constitutive relationship does not change before and after the damage caused by the coupling of water chemistry and cyclic water invasion. However, the effective stress in the constitutive model will change. Therefore, based on the principle of damage mechanics, the basic form of the material's damage constitutive equation is [19-21]

$$
\varepsilon=\frac{\bar{\sigma}}{E}=\frac{1}{E} \cdot \frac{\sigma}{(1-D)},
$$

where $\varepsilon$ is the rock strain in different states, $\sigma$ is the nominal stress on the rock, $\bar{\sigma}$ is the effective stress on the rock, $E$ is the initial elastic modulus of the material, and $D$ is the damage variable.

By combining formulas (7) and (8), a constitutive model of rock damage under the coupling of water chemistry and cyclic invasion can be deduced:

$$
\sigma=E_{n} \cdot\left(\exp \left(-\left(\frac{\varepsilon}{\lambda}\right)^{m}\right)\right) \cdot \varepsilon
$$

4.1. Evaluation of Rock Damage Constitutive Model. According to the uniaxial compression test results of rock under the coupling of water chemistry and cyclic invasion, the comparative analysis of the statistical damage constitutive model under the coupling of water chemistry and cyclic invasion is carried out (Figure 6).

The damage constitutive model established in the paper can effectively describe the characteristics of the test curve, and the description accuracy is greater than $90 \%$, which illustrates the effectiveness of the established model (Figure 6). Because the damage constitutive model was built without considering the initial compaction stage, some model curves show deviations during the compaction stage of the stress-strain curve, which limits the accuracy of the constitutive model to some extent. However, the damage constitutive model considering the coupling effect of water chemistry and cyclic invasion and can describe the characteristics of rock deformation curve.

\section{Conclusion}

Taking an open pit as the tailings pond, the change in rock strength considering the degradation and damage caused by the coupling effect of water chemistry and cyclic invasion was analyzed using uniaxial compression tests. A constitutive model for rock damage under the coupling of water chemistry and cyclic invasion was introduced. The main research conclusions include

(1) The coupling effect of water chemistry and cyclic invasion decreases rock strength. Test results show that the peak strength and elastic modulus of the rock gradually decrease as the number of cycles increases. Specifically, the more the number of cycles is, the more obvious the damage of the peak strength and elastic modulus of the rock is. The weakening speed of the peak strength is higher than that of the elastic modulus.

(2) The acidity and alkalinity of the fluid also degrade rock strength, acidic and alkaline conditions have a significant weakening effect on the peak strength and elastic modulus of the rock, and the weakening effect of the neutral condition on the rock is slightly weaker; acidic fluids degrade rock strength more that alkaline solutions. The change curve relative to the number of cycles, $\mathrm{pH}$ level, peak strength, and elastic modulus of the rock was fit.

(3) Based on the principle of damage mechanics, the HCM coupling damage variable is defined. Based on the Weibull distribution theory and the strain equivalent principle, a coupling that considers water chemistry and cyclic water intrusion is constructed. The effect of the constitutive model of rock damage is verified by comparison with experimental results.

\section{Data Availability}

The processed data required to reproduce these findings cannot be shared at this time as the data also forms part of an ongoing study. 


\section{Conflicts of Interest}

The authors declare that they have no conflicts of interest.

\section{Acknowledgments}

This work was supported by the National Natural Science Foundation of China (no. 51909149) and Opening Foundation of Shandong Key Laboratory of Civil Engineering Disaster Prevention and Mitigation (no. CDPM2019ZR10).

\section{References}

[1] Z. Qin, H. Fu, and X. Chen, "A study on altered granite mesodamage mechanisms due to water invasion-water loss cycles," Environmental Earth Sciences, vol. 78, no. 14, p. 428, 2019.

[2] Z. Qin, X. Chen, and H. Fu, "Damage features of altered rock subjected to drying-wetting cycles," Advances in Civil Engineering, vol. 2018, Article ID 5170832, 10 pages, 2018.

[3] X. Chen, P. He, Z. Qin et al., "Statistical damage model of altered granite under dry-wet cycles," Symmetry, vol. 11, no. 1, 2019.

[4] L. Li, S. Sun, J. Wang, W. Yang, S. Song, and Z. Fang, "Experimental study of the precursor information of the water inrush in shield tunnels due to the proximity of a water-filled cave," International Journal of Rock Mechanics and Mining Sciences, vol. 130, Article ID 104320, 2020.

[5] W. T. Li, N. Yang, and T. C. Li, "Implementation of bolt broken failure in FLAC3D and its application," Chinese Journal of Rock Mechanics and Engineering, vol. 35, no. 4, pp. 753-767, 2016.

[6] T. Waragai, "The effect of rock strength on weathering rates of sandstone used for Angkor temples in Cambodia," Engineering Geology, vol. 207, pp. 24-35, 2016.

[7] X. Liu, Z. Wang, Y. Fu et al., "Macro/microtesting and damage and degradation of sandstones under dry-wet cycles," $A d$ vances in Materials Science and Engineering, vol. 2016, Article ID 7013032, 16 pages, 2016.

[8] G. Wang, W. Han, Y. Jiang, H. Luan, and K. Wang, "Coupling analysis for rock mass supported with CMC or CFC rockbolts based on viscoelastic method," Rock Mechanics and Rock Engineering, vol. 52, no. 11, pp. 4565-4588, 2019.

[9] X.-X. Yang and W.-G. Qiao, "Numerical investigation of the shear behavior of granite materials containing discontinuous joints by utilizing the flat-joint model," Computers and Geotechnics, vol. 104, pp. 69-80, 2018.

[10] Q. Yao, T. Chen, M. Ju, S. Liang, Y. Liu, and X. Li, "Effects of water intrusion on mechanical properties of and crack propagation in coal," Rock Mechanics and Rock Engineering, vol. 49, no. 12, pp. 4699-4709, 2016.

[11] K. Bian, J. Liu, W. Zhang, X. Zheng, S. Ni, and Z. Liu, "Mechanical behavior and damage constitutive model of rock subjected to water-weakening effect and uniaxial loading," Rock Mechanics and Rock Engineering, vol. 52, no. 1, pp. 97-106, 2019.

[12] Z. Zhao, J. Yang, D. Zhang, and H. Peng, "Effects of wetting and cyclic wetting-drying on tensile strength of sandstone with a low clay mineral content," Rock Mechanics and Rock Engineering, vol. 50, no. 2, pp. 485-491, 2017.

[13] X. Chen, P. He, and Z. Qin, "Damage to the microstructure and strength of altered granite under wet-dry cycles," Symmetry, vol. 10, no. 12, p. 716, 2018.

[14] K. Xie, D. Jiang, Z. Sun, J. Chen, W. Zhang, and X. Jiang, "NMR, MRI and AE statistical study of damage due to a low number of wetting-drying cycles in sandstone from the three gorges reservoir area," Rock Mechanics and Rock Engineering, vol. 51, no. 11, pp. 3625-3634, 2018.

[15] P. Kang, L. Hong, Y. Fazhi, Z. Quanle, and L. Zhaopeng, "Effects of temperature on mechanical properties of granite under different fracture modes," Engineering Fracture Mechanics, vol. 226, p. 106838, 2020.

[16] T. Saksala, "Modelling of dynamic rock fracture process with a rate-dependent combined continuum damage-embedded discontinuity model incorporating microstructure," Rock Mechanics and Rock Engineering, vol. 49, no. 10, pp. 39473962, 2016.

[17] D. Kundu and R. D. Gupta, "Estimation of \$rm P[Y $\ll]$ Xfor Weibull Distributions," IEEE Transactions on Reliability, vol. 55, no. 2, pp. 270-280, 2006.

[18] T. Wong, R. H. C. Wong, K. T. Chau et al., "Microcrack statistics, Weibull distribution and micromechanical modeling of compressive failure in rock," Mechanics of Materials, vol. 38, no. 7, pp. 664-681, 2006.

[19] D. Krajcinovic, "Damage mechanics," Ceskoslovensky Casopis Pro Fyziku Sekce A, vol. 8, no. 2-3, pp. 117-197, 1989.

[20] K. Peng, J. Zhou, Q. Zou, and F. Yan, "Deformation characteristics of sandstones during cyclic loading and unloading with varying lower limits of stress under different confining pressures," International Journal of Fatigue, vol. 127, pp. 82-100, 2019.

[21] K. Peng, J. Zhou, Q. Zou, and X. Song, "Effect of loading frequency on the deformation behaviours of sandstones subjected to cyclic loads and its underlying mechanism," International Journal of Fatigue, vol. 131, p. 105349, 2020. 